\title{
El Aprendizaje de Relaciones Simétricas en los Niños
}

\author{
José Carlos Rivera Benavides \\ Universidad Nacional Mayor de San Marcos, Lima, Perú \\ Recibido el 29 de abril 2018. Aceptado el 21 de junio 2018
}

DOI: https://doi.org/10.33017/RevECIPeru2018.0019/

\section{Resumen}

Este artículo contiene dos partes, una introductoria y la otra con el desarrollo de un programa educativo para niños de 5 a 7 años de edad. La teoría y hallazgos de la psicología genética demostraron que los niños entre los 5 a 7 años de edad poseen nociones intuitivas sobre el espacio, es decir, nociones de espacio basadas en los datos perceptivos de los objetos (datos de carácter visuotactilokinestésicos) y en las imágenes espaciales que surgen de la actividad manipulatoria-perceptiva del niño sobre los objetos que percibe permitiéndole agrupar los objetos en colecciones figurativas y no figurativas, las cuales los psicólogos genéticos Jean Piaget y Bärbel Inhelder han descrito en términos de simetrías simples: espejo, axial y de rotación. Este dominio intuitivo de las simetrías en el niño nos ha llevado a proponer un conjunto de actividades de aplicación de las reglas simétricas mencionadas para que los niños logren descubrir con la guía del maestro, las propiedades intra e interfigurales de las formas geométricas elementales para lo cual se han diseñado tres fases, seguidas de una cuarta en la que el niño resuelve problemas fractales simples mediante reglas de composición simétricas adquiridas en las tres primeras fases. En base al marco teórico adoptado y algunos antecedentes, se propone el programa Desarrollo de la Intuición Geométrica (DIG) organizada en dos módulos (I y II) con dos fases por módulo: primera y segunda fases en el módulo I y, tercer y cuarta en el módulo II.

Descriptores: noción intuitiva del espacio, simetría simple, formas geométricas elementales, fractales simples, reglas de composiciones simétricas.

\begin{abstract}
This article contains two parts, one introductory and the other with the development of an educational program for children from 5 to 7 years of age. The theory and findings of genetic psychology showed that children between 5 to 7 years of age possess intuitive notions about space, that is, notions of space based on the perceptual data of objects (visuotactilokinestesicos character data) and on the spatial images that arise from the manipulatoryperceptive activity of the child on the objects he perceives, allowing him to group objects in figurative and nonfigurative collections, which genetic psychologists Jean Piaget and Bärbel Inhelder have described in terms of simple symmetries: mirror, axial and of rotation. This intuitive mastery of the symmetries in the child has led us to propose a set of activities to apply the mentioned symmetrical rules so that the children can discover with the guidance of the teacher, the intra- and inter-figurative properties of the elementary geometric forms for which three phases have been designed, followed by a fourth in which the child solves simple fractal problems through symmetric composition rules acquired in the first three phases. Based on the theoretical framework adopted and some background, we propose the Development of Geometric Intuition (DIG) program organized into two modules (I and II) with two phases per module: first and second phases in module I and third and fourth in module II.
\end{abstract}

Keywords: intuitive notion of space, simple symmetry, elementary geometric shapes, simple fractals, symmetric composition rule. 


\section{Introducción}

El conocimiento como aprehensión de los objetos, implica un primer nivel de contacto directo con el aspecto fenoménico del objeto, la percepción directa. Al respecto, Jean Piaget [1] dijo:

"Todo dato perceptivo aporta una significación, sin salir del campo de la percepción, pero los "significantes" y "significados" propios a esas significaciones perceptivas no sobrepasan el cuadro de los "indicios" y permanecen así relativamente indiferenciados e intercambiables, por oposición a los "símbolos" y a los "signos" que son significantes diferenciados de sus significados y de menos en menos intercambiables con ellos" (Piaget, 1975, p. 357).

Un indicio perceptivo permite el reconocimiento de la configuración de un objeto. Esta recognición ocurre a los 7-8 meses del período sensoriomotriz de la inteligencia, a lo que Piaget denominó la permanencia del objeto, y también ocurre en los períodos representativos de la inteligencia preoperatoria, cuando el niño desde los 4-5 años, por ejemplo, reconoce una figura geométrica como idéntica a pesar de sus cambios en el espacio visual o tactilokinestésico.

Los modos en que los niños, durante el período del pensamiento preoperatorio relacionan entre sí diversas figuras geométricas, se basan en agrupaciones que Jean Piaget y Bärbel Inhelder [2] denominaron colecciones, que en los niños entre 2 y 4 años consiste en formar objetos significativos ("un muñeco", "un carrito", "la casa" o cualquier otra composición con una figura sugestiva); a estas las llamaron más particularmente colecciones figurales significativas. Más tarde, entre los 5 a 6 años, los niños pasan a realizar alineamientos por semejanzas parciales entre las formas de las figuras geométricas; a estas colecciones las llamaron colecciones no figurales.

"En una palabra, la colección figural constituiría una figura precisamente en virtud de los enlaces de sus elementos como tales, mientras que las colecciones no figurales y las clases serían independientes de toda figura, incluyendo también los casos en las que están simbolizadas por figuras, y a pesar de que puedan también dar lugar a isomorfismos con estructuras topológicas" (Piaget e Inhelder, 1967, p. 31).

Efectivamente, en esta obra los autores sostuvieron, que en el nivel de las colecciones los niños establecen relaciones de semejanzas y diferencias y, de la parte al todo subordinadas a las configuraciones perceptivas, y por consiguiente limitadas al ámbito de las partes y totalidades continuas o espaciales (partición de un objeto o de una figura y recomposición de la totalidad de uno solo de esos conjuntos a partir de esos segmentos). Así, lo ilustraron con las figuras del Capítulo I donde se observa que una característica fundamental de las colecciones figurales es la disposición simétrica de los diversos elementos en las totalidades.

Piaget et Inhelder, en sus estudios sobre la noción de orden topológico [3] establecieron que los niños del período preoperatorio logran componer una sucesión de bolillas de diferente color cuando el experimentador les presenta un conjunto de ellas ensartadas de manera lineal o circular. Esto evidencia el dominio de las correspondencias simétricas de los elementos y de la simetría axial de las figuras como totalidad.

Piaget, en La epistemología del espacio [4] señaló el papel de la imagen mental en la elaboración de las nociones espaciales geométricas.

"La imagen no es más que un símbolo, cuya elaboración no se debe únicamente a la percepción, sino a un juego de imitaciones interiorizadas. (...) en el nivel preoperatorio del pensamiento del niño la imagen visual permanece en actitud estática, $y$ resulta incapaz de representar las transformaciones más elementales. Si luego adquieren una cierta movilidad (...) por la influencia de aportes exteriores a ella y proporcionados esencialmente por las operaciones intelectuales, a partir del nivel (hacia los 7-8 años) en que estas comienzan a constituirse. (...) En suma, la intuición geométrica es de naturaleza principalmente operatoria, y si se acompaña por imágenes más o menos adecuadas ello ocurre en virtud de la homogeneidad, especial para el espacio, que existe entre los significantes simbólicos visuales y los significados espaciales" (Piaget, 1971, pp. 4-5).

Para la psicología genética la fuente de las imágenes mentales se encuentra en las imitaciones interiorizadas y tienen un rol preponderante en la representación mental. Sobre el proceso de formación de las nociones espaciales, Piaget et Inhelder [3] dijeron:

"La interiorización de las acciones espaciales se efectúa de otro lado según etapas muy graduales, 
que nos ha sido posible seguir paso a paso. Después de la actividad sensoriomotriz elemental, ligada a la percepción del objeto, viene la acción evocada en imaginación, pero después únicamente que ella ha sido ejecutada materialmente" (Piaget et Inhelder, 1972, p. 530).

Por ejemplo, los niños pequeños frente a un nudo un poco abierto y otro un poco más cerrado, no los ven o conciben como homeomorfos sino hasta que hayan tirado de los extremos (Op. Cit., p. 129, figuras 11 a 17).

"Tal es la intuición elemental propia de nuestro estadio I (entre 4-5 años). Con el estadio II (de 4-5 a 7-8 años) la coordinación creciente de las acciones exteriores se traduce por una coordinación interna de sus esquemas (es decir de los esbozos interiorizados) pero que proceden todavía por tanteos y no alcanzando más que anticipaciones fragmentarias de acciones ulteriores posibles: se puede hablar entonces de una articulación progresiva de las intuiciones" (Op. Cit., p. 530).

$\mathrm{Si}$ bien, las colecciones figurales son muy dependientes de la subjetividad infantil, y muy variadas, incluso las no figurales, ellas poseen un rasgo común, la simetría, la cual ya se plasma incluso en los dibujos del tipo "monigotes", que evidencian el dominio de lo reverso y anverso en el espacio figural, nota característica de la simetría axial gracias a la cual los cuerpos son dibujados con partes iguales y opuestas.

Para concluir nuestra introducción, consideramos pertinente señalar que existen propuestas de programas de enseñanza de la geometría. Una de ellas es Aprender geometría doblando papel [5], es un maravilloso esfuerzo de trabajo empírico que nos ofrece el autor, quien propone que el círculo como figura generadora de las formas euclideanas, es una herramienta que, mediante sus dobleces simétricos le dan al niño de 6 a 7 años, conceptos que lo integran a los conceptos esenciales de las propiedades de las figuras euclideanas. El libro, está programado hasta los 12 años.

Otro trabajo importante para niños de $1^{\circ}$ a $3^{\circ}$ grado, El estudio de las figuras y de los cuerpos geométricos [6], enfatiza la obtención de formas mediante pliegues de figuras euclideanas, para obtener otras figuras diferentes, por ejemplo, obtener ocho triángulos en base al doblado sucesivo de un cuadrado, etc., induciendo a los niños así a las nociones de equivalencias entre las diferentes formas por el seccionamiento de pliegues que son los medios de transformación para obtener figuras diferentes (pero con igual superficie).

Esta propuesta, muy próxima a la nuestra, difiere en que nosotros introducimos la solución de problemas fractales, con lo cual la dimensión es variable y de la repetición de las formas se pueden componer otras formas hasta aproximarse al círculo incluso. Esto es posible por los mecanismos de la percepción y la imagen como lo señalan los psicólogos genéticos.

Por último, los conceptos intuitivos de la geometría se relacionan íntimamente al desarrollo posterior de la noción de conservación de la superficie, tal como lo demostró Vinh Bang [7] en niños de 4 a 14 años; y más interesante aún, por su relación con las nociones aritméticas, es la relación de la parte al todo, la de mitad continua y discontinua, abordados por Silvia Parrat-Dayant y Jacques Vonéche [8].

Así como las dos últimas contribuciones referidas pueden ser consultadas para ampliar la perspectiva de las tareas descritas, ponemos a disposición de los maestros de la Educación Básica la aplicación del programa Desarrollo de la Intuición Geométrica (DIG) expuesto en la siguiente sección, cuyos resultados sería interesante comunicarlos.

\section{Programa Desarrollo de la Intuición Geométrica}

Módulo I: Descomposición/Reunión.

Primera Fase. Se inicia poniendo en evidencia la capacidad espontánea del niño de encontrar el seccionamiento, mediante un trazo de recta, de figuras no geométricas que perceptivamente son diferentes por la orientación en el plano (Fig. 1). Se le solicita al niño rayar las figuras por la mitad. 


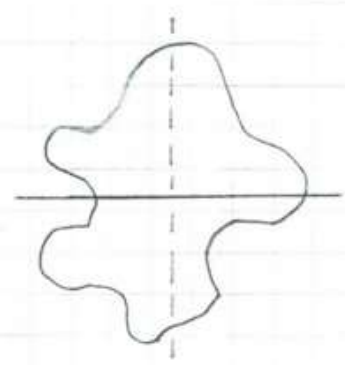

SIN ORIENTACIÓN DEFINIDA

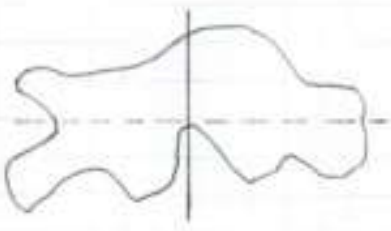

CON OFENTACIÓN HOGIZONTAL.

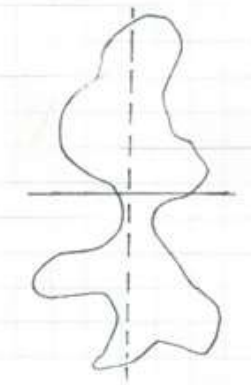

CON ORIENTACIÓN VERTICAL

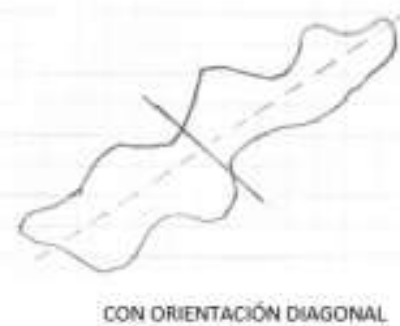

Figura 1: Simetría Espontánea en Cuerpos Irregulares (con extensión y orientación diferentes).

Segunda Fase. Es el procedimiento de aprendizaje inductivo. Consiste en "hacer descubrir" al niño luego de seccionar una figura geométrica simple por la mitad - que hay otros modos de hacerlo, de modo tal que se obtengan muchas mitades similares a la forma original. Esta comprobación se hace por comparación de las figuras seccionadas (Figs. 2.1, 2.2 y 2.3).
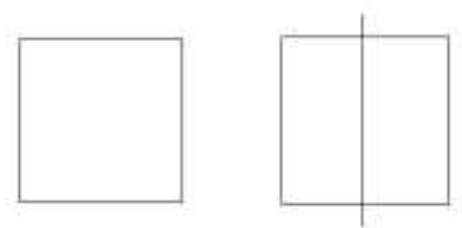

PFIMERA INDUCCION

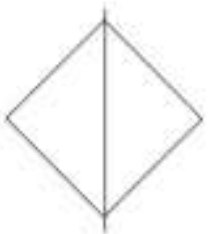

SE GUNBM INoucción.

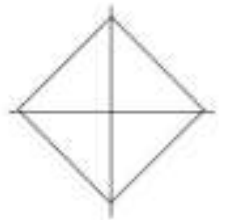

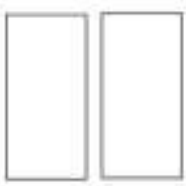

COMPARACión

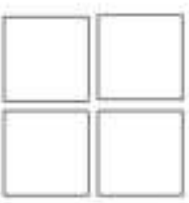

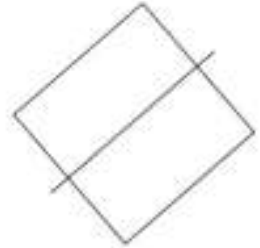

COMPARACION
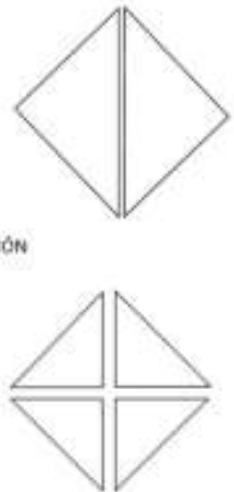

Figura 2.1. Simetría Espontánea en Figuras Geométricas en base a un cuadrado.
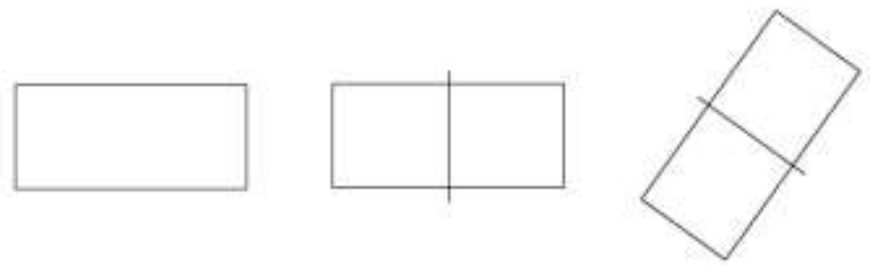

INDUCCIÓN

COMPARACIÓN
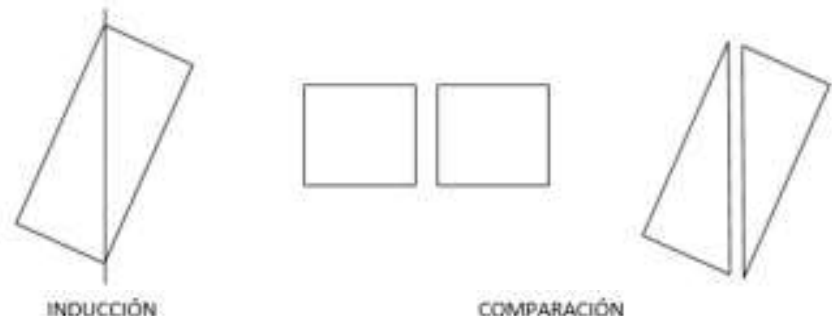

COMPARACIÓN
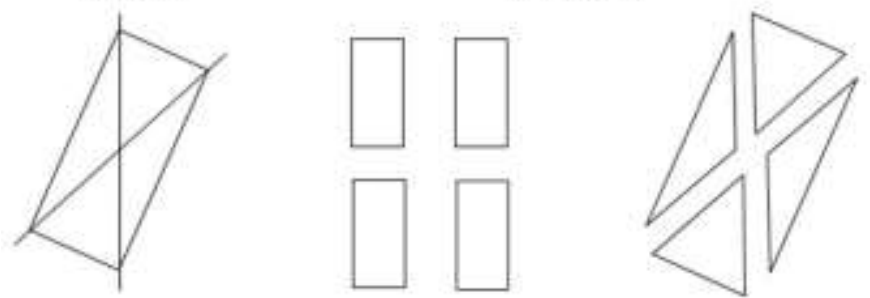

Figura 2.2. Simetría Espontánea en Figuras Geométricas en base a un rectángulo.
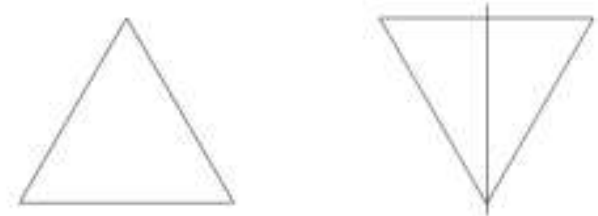

INDUCCIÓN

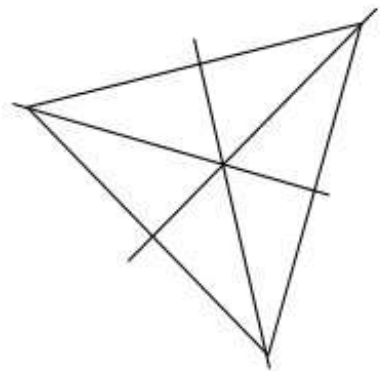

CONPARACOON
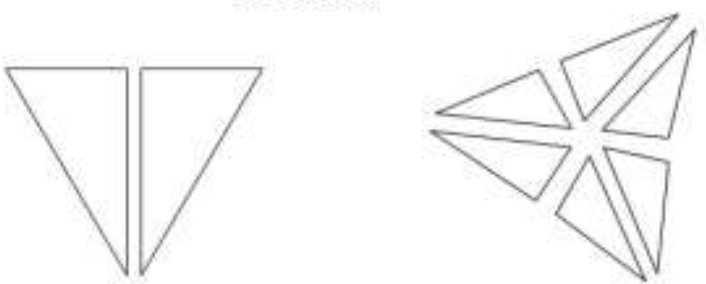

Figura 2.3. Simetría Espontánea en Figuras Geométricas en base a un triángulo. 


\section{Módulo II: Composición}

Tercera Fase. Consiste en la inducción del descubrimiento, del completamiento o generación de un cuerpo por simetría especular simple, en primer lugar (Fig. 3.1) y complejas en segundo lugar (Fig. 3.2).

Figuras Simples. - Se procede mostrándole al niño un triángulo rectángulo, por ejemplo, y le solicitamos que dibuje lo que falte para obtener otra figura:
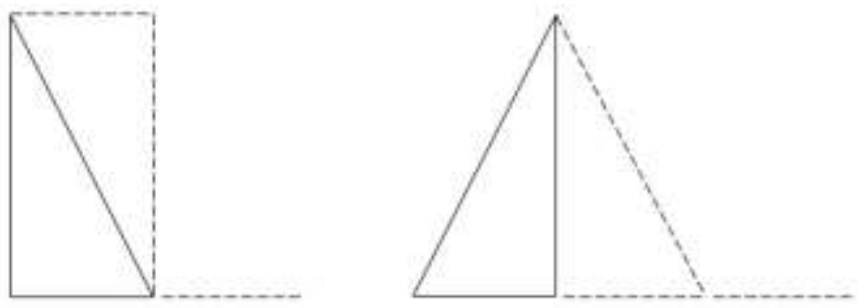

Figura 3.1. Composición de Figuras Simples.

Si en esta fase el niño no realiza ningún dibujo, o lo hace equivocadamente se gira la figura sobre uno de sus lados, y se vuelve a solicitar el dibujo. Este ejercicio se realiza en todos los planos adyacentes y con diferentes figuras.

Figuras Complejas. - Por tratarse de figuras irregulares, al inicio se recomienda utilizar un patrón o modelo (un trapecio) de papel para realizar la copia simétrica, como en la figura 3.2.

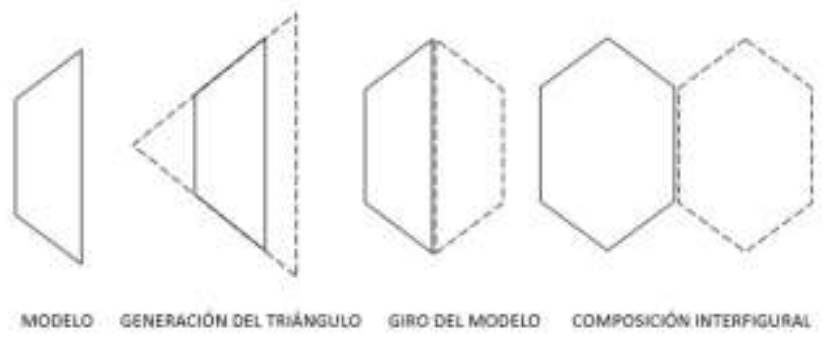

Figura 3.2. Composición de Figuras Complejas.

En el caso que el niño de una respuesta de tipo perceptual (generación del triángulo) se hace girar el modelo sobre el eje mayor y luego se procede con otras figuras más complejas, introduciendo al niño a las composiciones interfigurales.

Cuarta Fase. Composición de Fractales.

En esta fase se le plantea al niño la construcción por dibujo repetitivo, de una forma que da por resultado otra igual y de mayor dimensión; a partir de un modelo (M) como en la figura 4.1.

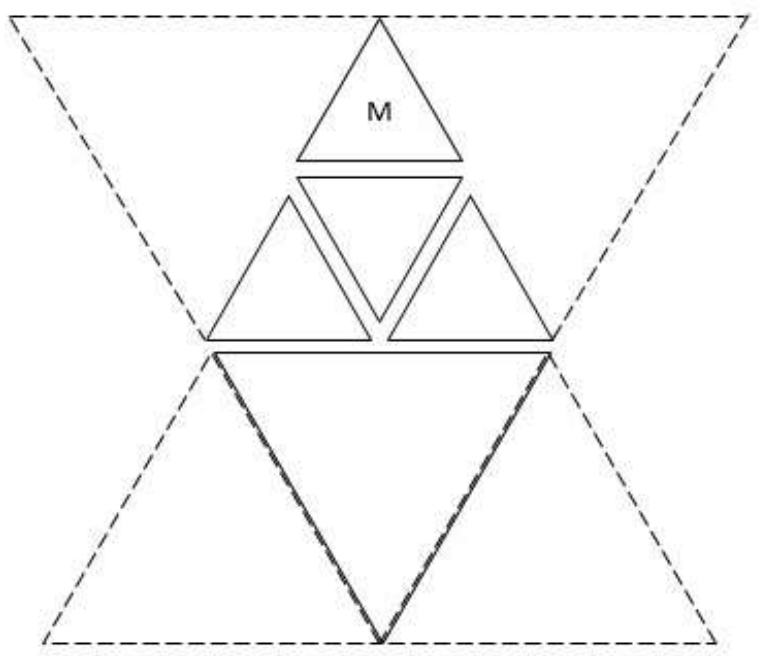

Figura 4.1. Fractal simple en base al triángulo.

Se le solicita, entonces que dibuje las figuras interiores en el triángulo inferior. Luego por recorte de los triángulos mayores se comprueba con el niño el acierto del dibujo. El caso del cuadrado, que es una figura simple al fraccionarse, también plantea dificultades en la aplicación de las reglas de simetría, pues la orientación relativa entre las figuras requiere reglas simétricas más dinámicas. Después del primer ejercicio en esta fase (Fig. 4.1), se procede presentando el modelo de la figura 4.2.1:

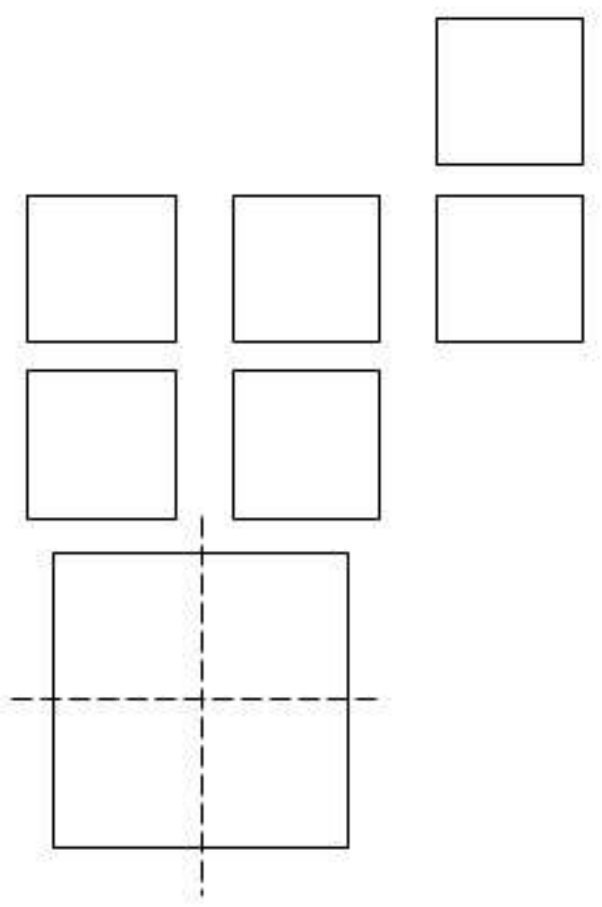

Figura 4.2.1. Modelo de fractal simple. 
Se le solicita al niño, que teniendo el modelo bajo su mirada dibuje otro similar, completando las figuras interiores y exteriores que faltan. Es altamente probable que la respuesta del niño se dé como sigue:
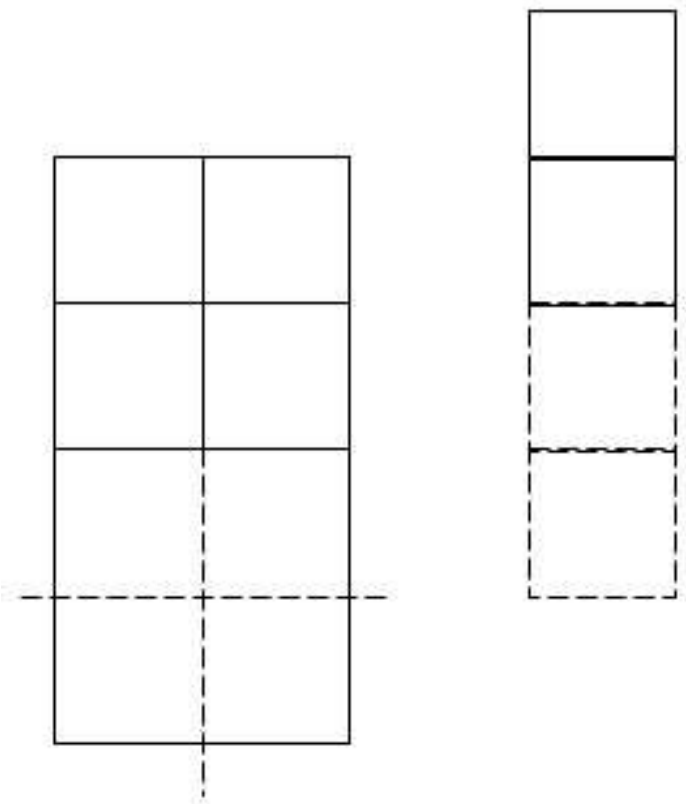

Figura 4.2.2. Generación de fractal simple según modelo.

Al separar las figuras en el sentido de una doble $L$, se obtienen dos figuras simétricas, pero se le hace entender al niño que las figuras están creciendo en una dirección, para formar una figura igual y mayor.
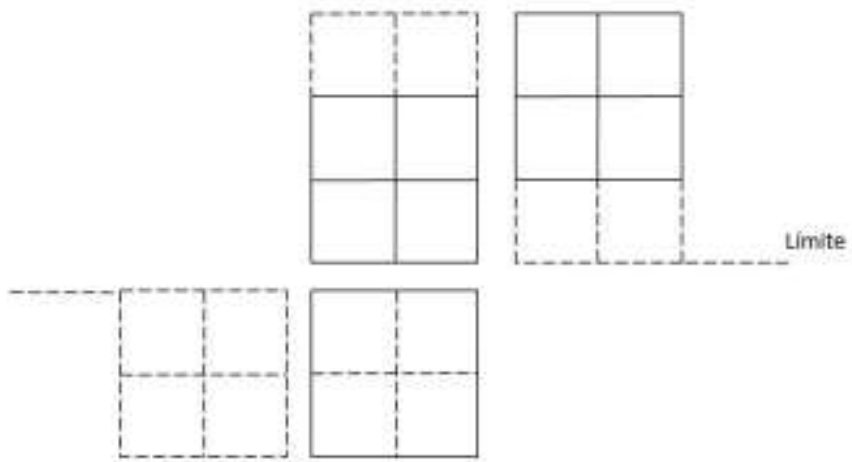

Figura 4.2.3. Límite de un fractal simple.

Las líneas punteadas indican la regla que ha de seguir el niño. A continuación, se repite un ejercicio similar al de la figura anterior con más divisiones y otra disposición espacial como en la siguiente figura.
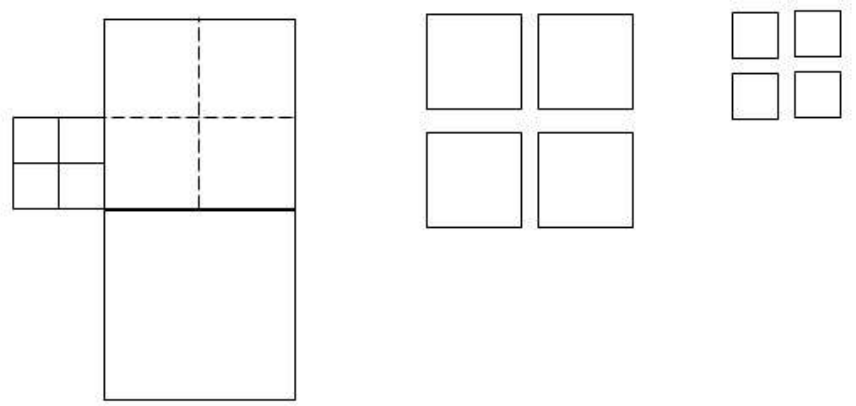

Figura 4.2.4. Modelo de ejercicio.

Se le solicita al niño que reproduzca el modelo (fig. 4.2.4) completando lo que falta para que "todo quede igual".

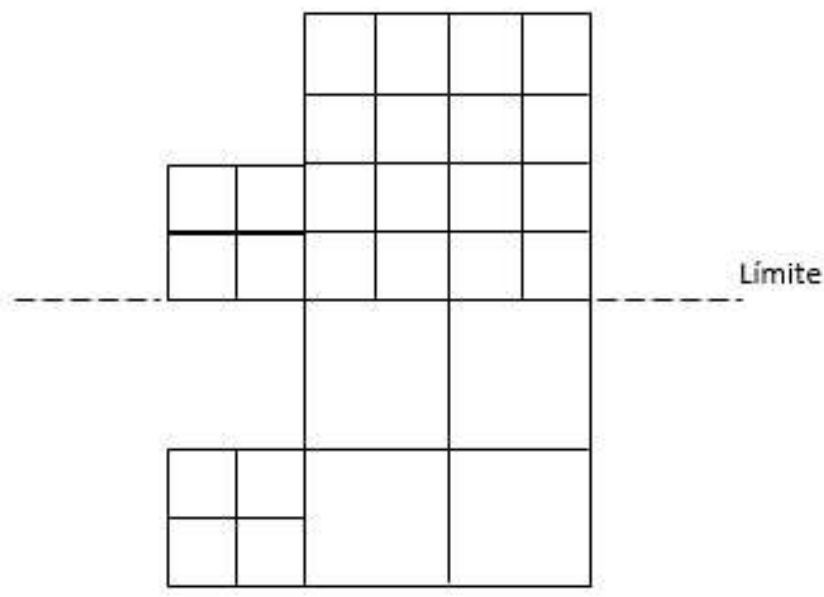

Figura 4.2.5. Recomposición de un fractal simple.

\section{Referencias}

[1] J. Piaget, Les mecanismes perceptifs, $2^{\circ}$ éd. (Presses Universitaires de France, Paris, 1975), pp. 355-358.

[2] J. Piaget y B. Inhelder, Génesis de las estructuras lógicas elementales. Clasificaciones $y$ seriaciones, $1^{\circ}$ Ed. (Guadalupe, Buenos Aires, 1967), pp. 2958.

[3] J. Piaget et B. Inhelder, La representation de l'espace chez l'enfant, $2^{\circ}$ éd. (PUF, Paris, 1972), pp. 128-131; 526-533.

[4] J. Piaget, Trabajos del año 1960-61 y Sexto Simposio (19-24 de junio de 1961) del Centro Internacional de Epistemología Genética en J. Piaget y Colabs., La epistemología del espacio, 1ํㅡ. (El Ateneo, Buenos, 1971), pp. 3-11.

[5] M. Hidalgo, Aprender geometría doblando papel. Módulos de aprendizaje con geometría constructiva, Prim. Ed. (Lima, 2007), pp. 55-60. 
[6] C. Broitman y $\mathrm{H}$. Itzcovich, El estudio de las figuras $y$ de los cuerpos geométricos. Actividades para los primeros años de escolaridad, 2o Reimp. (Novedades Educativas, Argentina, 2007), pp. 87-95.

[7] V. Bang, De l'intuiton geometrique en V. Bang et E. Lunzer, Conservation spatiales, 1er éd. (PUF, Paris, 1965), pp. 39-58.
[8] S. Parrat-Dayan et J. Vonéche, Conservation, notions et practiques cognitives: étude de leurs interrelations en J. Bideaud, Cl. Meljac et J. P. Fisher, Les chemins du nombre, $2^{\circ}$ éd. (Presses Universitaires de Lille, Francia, 1991), p. 91105.

Autor correspondiente: J.C. Rivera E-mail: jriverab@unmsm.edu.pe 